\title{
Gall bladder function after endoscopic sphincterotomy
}

\section{A Desa, P A Grace, $M$ N Vipond, B Henderson, J N Thompson}

Departments of Surgery and Diagnostic Radiology, Royal Postgraduate Medical School, Hammersmith Hospital, London W12 0NN L A Desa, FRCS, senior registrar

P A Grace, FRCS, senior registrar

B Henderson, DRI, superintendent radiographer J N Thompson, FRCS, senior lecturer

\section{Academic Surgical Unit, St} Mary's Hospital, London W2

M N Vipond, FRCs, research fellow

Correspondence to: $\mathrm{Mr} \mathrm{J} \mathrm{N}$ Thompson, Department of Surgery.

BrMed f 1990;300:1111 been reported.

\section{Patients, methods, and results}

Endoscopic sphincterotomy with extraction of the stones is often the only treatment for stones in the bile duct in patients considered unfit for surgery. Most of these patients fare well even when they have stones in the gall bladder; cholecystectomy for biliary colic, acute cholecystitis, or jaundice was necessary in less than $15 \%$ followed up for up to seven years. ${ }^{12}$ After the procedure patients retain their gall bladder and have an incompetent lower bile duct sphincter; little is known about the subsequent function of the gall bladder, although changes in the metabolism of bile acids have

In a patient who had recently had an endoscopic sphincterotomy to remove stones we noted the absence of filling of the gall bladder during biliary excretion scintigraphy, although the cystic duct had been patent at endoscopic cholangiography. We therefore undertook a prospective study of gall bladder function after endoscopic sphincterotomy for ductal stones.

Patients were included in the study if they had had endoscopic sphincterotomy for ductal stones; had a patent cystic duct with filling of the gall bladder evident on endoscopic cholangiography (figure $(a)$ ); had had clearance of their ductal stones confirmed by cholangiography; had had an uncomplicated recovery; and gave informed consent.

After a 10 hour fast scintigraphic imaging was performed after intravenous injection of HIDA $(2,6-$ diethylphenylcarbamoylmethyliminodiacetic acid) labelled with $115 \mathrm{MBq}$ technetium-99m. Anterior images of the right upper abdomen were obtained by using $60 \mathrm{~s}$ frames for 40 minutes with the patient supine. Delayed anterior and right anterior oblique images were obtained up to two hours after injection with the patient erect.

We studied six men aged $67-89$ (median 79.5 years) three to 120 days (median 20) after endoscopic sphincterotomy. All were asymptomatic at the time of scintigraphy (serum bilirubin concentrations $<30$ $\mu \mathrm{mol} / \mathrm{l}$ ). There was prompt uptake of the isotope by the liver, with later visualisation of both the extrahepatic biliary tree and the duodenum (figure $(b)$ ) in all patients; none showed filling of the gall bladder despite delayed imaging.

\section{Comment}

Obstruction of the cystic duct, prolonged fasting, chronic alcoholism, parenteral nutrition, previous cholecystectomy, and eating within two hours of a radiotracer injection are associated with non-visualisation of the gall bladder on excretion scintigraphy. None of these applied to our patients, although we could not completely exclude the possibility that asymptomatic obstruction of the cystic duct had occurred since endoscopic cholangiography. Nonvisualisation of the gall bladder has been reported in $10 \%$ of asymptomatic subjects with stones in the gall bladder, ${ }^{4}$ though higher figures have been reported for patients with symptomatic disease. ${ }^{5}$

Sphincterotomy reduces the pressure in the common bile duct, which presumably causes a preferential flow of bile through the incompetent sphincter, the lack of any functional obstruction at the sphincter of Oddi preventing reflux into the gall bladder. Indeed, sphinc-

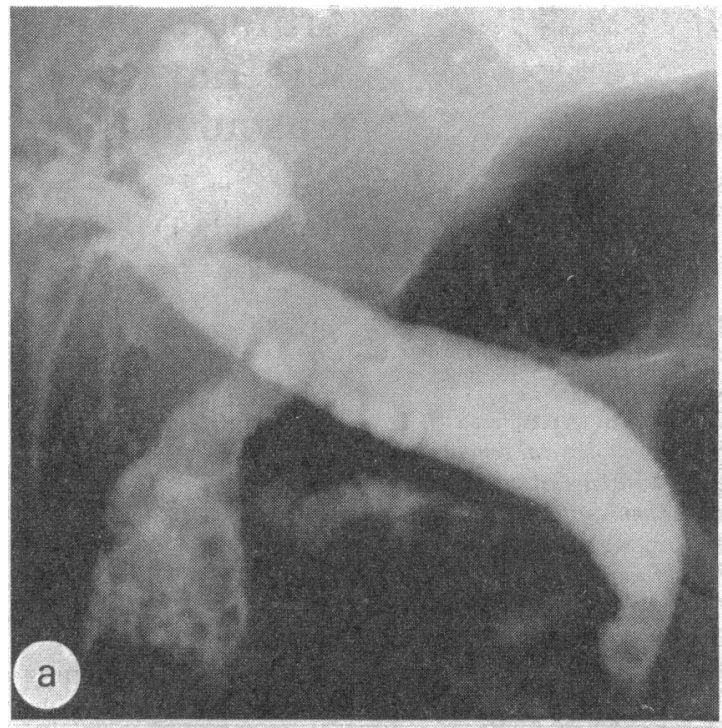

(a) Endoscopic cholangiogram showing cystic duct and filling of gall bladder at sphincterotomy for stones in bile duct. (b) Excretion scintigram after injection of HIDA in same patient after sphincterotomy showing bile duct and duodenum but no filling of gall bladder

terotomy in patients with a gall bladder reduces the total bile acid pool to levels seen after cholecystectomy.

This finding may have important implications. Firstly, any attempt to use bile salts to dissolve residual stones in the gall bladder may be ineffective as hepatic bile does not freely enter the gall bladder. Secondly, after extracorporeal shock wave lithotripsy stones or fragments are unlikely to pass spontaneously in patients who have had a sphincterotomy because of the absence of filling of the gall bladder to stimulate contraction. Thirdly, although excretion scintigraphy is often used to confirm acute gall bladder disease, ultrasound should be used in patients who have had a sphincterotomy. Fourthly, stagnant bile in a non-functioning gall bladder may predispose to the development of chronic infective changes or carcinoma. Finally, although endoscopic removal of bile duct stones gives reasonably good symptomatic results in unfit patients with a gall bladder, this management should be extended to other patients with caution because of the functional consequences of sphincterotomy.

We thank Professor J P Lavender for his help and advice.

1 Davidson BR, Neoptolemos JP, Carr-Locke DL. Endoscopic sphincterotomy for common bile duct calculi in patients with gallbladders in situ considered unfit for surgery. Gut 1988;29:114-20.

Martin DF, Tweedle DEF. Endoscopic management of common duct stone without cholecystectomy. Br f Surg 1987;74:209-11.

3 Sauerbruch T, Stellaard F, Paumgartner G. Effect of endoscopic sphincterotomy on bile acid pool size and bile acid composition in man. Digestion $1983 ; 27: 8-12$

4 Freitas JE, Bennet DMF. Asymptomatic cystic duct obstruction in chronic cholecystitis [Abstract]. I Nucl Med 1980;21:P17-8.

5 Rosenthall L, Shaffer EA, Lisbona R, Pare P. Diagnosis of hepatobiliary disease by ${ }^{*}$ Tc-HIDA cholescintigraphy. Radiolog $\nu$ 1978;126:467-74.

Accepted 22 February 1990 